\title{
Electrophysiologic actions of pirmenol in dogs with recent myocardial infarction
}

\begin{abstract}
The electrophyslologlc actlons of pirmenol, an Investlgational class I antiarrhythmic agent, were evaluated in eight anesthetized dogs, 5 to 10 days after anterior myocardial infarction. Before administration of the drug, programmed ventricular stimulation failed to initiate nonsustained or sustained ventricular tachyarrhythmias (VT) in any of the postinfarction dogs. After the cumulative administration of $2.5,5.0$, and $10.0 \mathrm{mg} / \mathrm{kg}$ pirmenol, programmed stimulation initiated sustained VT in six of the eight postinfarction dogs tested, with one additional dog responding with reproducible nonsustained VT (15 to 20 monomorphic complexes) after pirmenol administration. Only one of eight postinfarction dogs tested remained noninducible throughout the pirmenol dosing schedule. Administration of pirmenol tended to increase ventricular excitation thresholds, relative $(\rho<0.05$ after $10 \mathrm{mg} / \mathrm{kg})$ and effective refractory periods in ischemically injured ventricular myocardium, and increased the difference or disparity in relative $(p<0.05$ after 5.0 and $10.0 \mathrm{mg} / \mathrm{kg})$ and effective $(p<0.01$ after $2.5,5$, and $10, \mathrm{mg} / \mathrm{kg})$ refractory perlods between ischemically injured and normal noninjured ventricular myocardium. These findings suggest a potential for the provocation or aggravation of ventricular arrhythmias by pirmenol in the setting of recent myocardial infarction. (AM HEART $J$ 1986;112:752.)
\end{abstract}

Joseph J. Lynch, Ph.D., Lorenzo A. DiCarlo, M.D., Daniel G. Montgomery, B.S., Terek Hassan, B.S., and Benedict R. Lucchesi, Ph.D., M.D., Ann Arbor, Mich.

The recent increased use of antiarrhythmic drugs for the management of potentially serious cardiac arrhythmias has developed a greater awareness and appreciation of the untoward effects of such agents. Clinical studies using ambulatory monitoring in conjunction with exercise testing ${ }^{1}$ or electrophysiologic testing procedure ${ }^{2-4}$ have indicated that conventional and investigational antiarrhythmic agents possess the potential for aggravating or provoking potentially lethal arrhythmias. These findings emphasize the need for early detection of potential arrhythmogenic actions and investigation of the electrophysiologic mechanisms of arrhythmogenic activity of such agents to minimize the facilitation of arrhythmias in patients.

During the course of an ongoing evaluation of antiarrhythmic agents, a small subset of postinfarction dogs that failed to respond to programmed

From the Departments of Pharmacology and Internal Medicine, The University of Michigan Medical School.

Supported by National Institutes of Health, Heart, Lung, and Blood Institute, Grant HL-05806-25.

Received for publication Sept. 25, 1985; revision received Jan. 10, 1986; accepted Feb. 20, 1986

Reprint requests: Benedict R. Lucchesi, Ph.D., M.D., Department of Pharmacology, M7423 Medical Science Building I, The University of Michigan Medical School, Ann Arbor, MI 48109. ventricular stimulation with ventricular tachyarrhythmia were prepared. Previously, this laboratory reported the use of programmed stimulation testing in such nonresponsive postinfarction dogs in an investigation of the electrophysiologic actions and proarrhythmic potential of lidocaine. ${ }^{5}$ In the present investigation, postinfarction dogs determined to be nonresponsive to programmed stimulation testing in the pretreatment state were used to evaluate the electrophysiologic actions of pirmenol, an investigational class I antiarrhythmic agent with demonstrated efficacy in experimental arrhythmia models of varying etiology ${ }^{6.8}$ and in preliminary clinical evaluations. ${ }^{9.12}$ The results of this investigation suggest a potential for the facilitation or provocation of ventricular tachyarrhythmias by pirmenol in the presence of recent ischemic injury, possibly resulting from increased refractoriness in ischemically injured ventricular myocardium and an increased dispersion in refractoriness between normal noninjured and ischemically injured ventricular tissue.

\section{METHODS}

Anterior myocardial infarction. Eight male mongrel dogs ( 14.5 to $21.5 \mathrm{~kg}$ ) were anesthetized with intravenous sodium pentobarbital, $30 \mathrm{mg} / \mathrm{kg}$. The dogs were ventilated with room air with the use of a cuffed endotracheal tube and a Harvard respirator. Using aseptic technique, the left 
external jugular vein and left common carotid artery were isolated, and cannulae were inserted. A left thoracotomy was performed between the fourth and fifth ribs. The pericardium was opened and the heart was suspended in a pericardial cradle. The left anterior descending coronary artery was isolated at the tip of the left atrial appendage. A 19- or 20-gauge hypodermic needle was placed parallel to the left anterior descending coronary artery and a suture was passed around both the vessel and the needle. The suture was tied securely and the needle withdrawn. producing a critical stenosis. The artery was then occluded using a snare formed from a loop of polymeric silicone (Silastic, Dow Corning Midland, Mich.) tubing (RetractO-Tape, Medical Products, Sun Prarie, Wis.) passed through a polyethylene tube. Blood flow through the left anterior descending coronary artery was restored after 2 hours.

An epicardial bipolar electrode $(1 \mathrm{~mm}$ diameter silver electrodes embedded $3 \mathrm{~mm}$ apurt in acrylic) was sutured to the left atrial appendage for atrial pacing. A bipolar plunge electrode (25-gauge insulated stainless steel wire, 5 $\mathrm{mm}$ in length, $2 \mathrm{~mm}$ apart) was sutured into the interventricular septum for determination of right ventricular outflow tract ventricular excitation threshold voltage, refractory period, and for the introduction of ventricular extrastimuli during programmed stimulation. Silver disc electrodes were implanted subcutaneously for monitoring the ECG, the surgical incision was closed, and the animals were allowed to recover from surgical anesthesia. The animals received ampicillin, $10 \mathrm{mg} / \mathrm{kg}$ by subcutaneous injection twice daily, during their postinfarction convalescence.

Experimental protocol for electrophysiologic studies in the postinfarction dog. Postinfarction dogs were returned to the laboratory 5 to 10 days after surgical preparation. Initial programmed ventricular stimulation testing was performed while the animals were conscious, unsedated, and resting comfortably in a sling. Only postinfarction dogs that were not susceptible to the initiation of ventricular tachycardia during initial programmed stimulation testing were entered into the present investigation. After each animal was determined to be nonresponsive to programmed ventricular stimulation, it was reanesthetized intravenously with Dial (Ciba Pharmaceutical Co, Summit, N.J.) urethane solution (20\% ethylurea, $20 \%$ allobarbital, $0.5 \%$ urethane, $0.6 \mathrm{ml} / \mathrm{kg}$ ), ventilated as described previously, and the heart was reexposed at the fourth left intercostal space via a thoracotomy. With the use of 22-gauge hypodermic needles as introducers, one set each of bipolar (hook) wire electrodes (Teflon [Du Pont Co., Wilmington, Del.]-insulated, 30-gauge silver wire with the distal $2 \mathrm{~mm}$ tip exposed, $2 \mathrm{~mm}$ tip separation) was inserted into normal noninfarcted ventricular myocardium in the proximal left circumflex coronary artery distribution, and into ischemically injured ventricular myocardium just distal to the site of the left anterior descending coronary artery occlusion. The area of anterior myocardial infarction was identified visually and through palpation and verified by postmortem examination. The

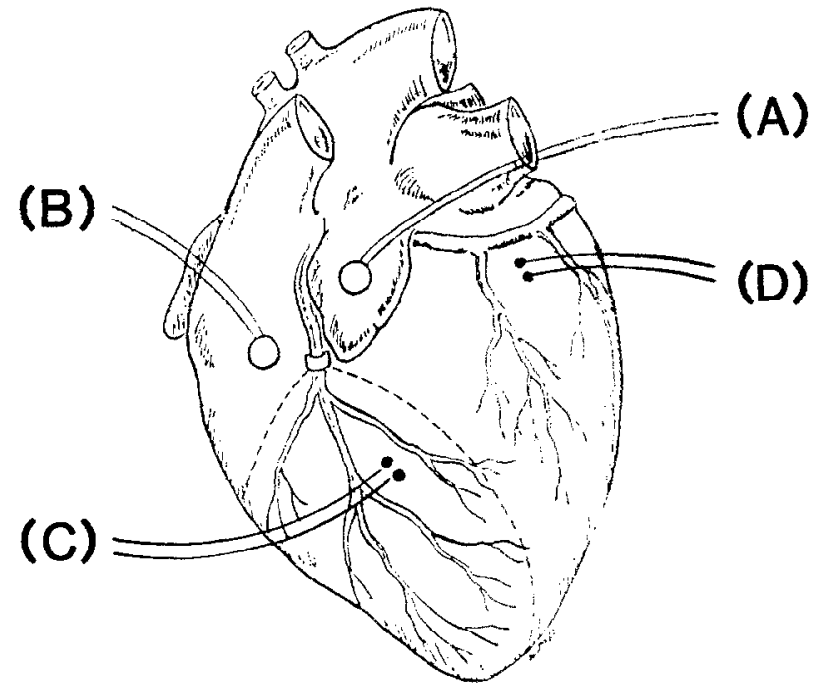

Fig. 1. Postinfarction dog model. On day of surgical preparation, anterior myocardial infarction is produced by 2-hour occlusion of left anterior descending coronary artery, followed by reperfusion through critical stenosis. Broken lines demarcate area at risk of myocardial infarction. During surgical preparation, epicardial bipolar electrode $(A)$ is attached to left atrial appendage for atrial pacing, and bipolar plunge electrode $(B)$ is inserted into interventricular septum adjacent to site of occlusion for determination of right ventricular outflow tract threshold voltage and refractory period, as well as for delivery of extrastimuli during programmed ventricular stimulation. At time of electrophysiologic testing, bipolar plunge electrodes are implanted into infarcted ventricular myocardium (C) and into normal noninjured ventricular myocardium (D) for construction of strength-interval curves.

normal zone and infarct zone bipolar electrodes were used to construct ventricular strength-interval curves for the determination of ventricular excitability and refractoriness in the two ventricular zones. The essential experimental features of this preparation are illustrated in Fig. 1.

Sixty minutes after placement of recording electrodes, pretreatment programmed ventricular stimulation was repeated to confirm the nonresponsiveness of the anesthetized animal, and electrophysiologic parameters were determined in normal noninfarcted and in infarcted ven. tricular myocardium. After baseline testing, intravenous pirmenol hydrochloride was administered in cumulative dusages of $2.5,5$, and $10 \mathrm{mg} / \mathrm{kg}$. The 2.5 and $5 \mathrm{mg} / \mathrm{kg}$ dosages were administered as 10 -minute infusions, while the last dosage was infused over a period of 20 minutes. Electrophysiologic testing and programmed ventricular stimulation were repeated 10 minutes after cessation of each of the three drug infusions.

Measurement of ventricular excitability and refractoriness in normal and infarcted myocardium. Measurements of ventricular excitability and refractoriness were determined through the construction of ventricular strength-interval curves at the electrodes sites in normal 
Table I. Responses to programmed ventricular stimulation

\begin{tabular}{|c|c|c|c|c|}
\hline \multirow[b]{2}{*}{ Animal No. } & \multirow[b]{2}{*}{ Predrug } & \multicolumn{3}{|c|}{ Pirmenol (mg/kg IV) } \\
\hline & & 2.5 & 5 & 10 \\
\hline 1 & NI & NI & $\begin{array}{l}\text { NSVT } \\
\text { (CL 155) }\end{array}$ & $\mathrm{NI}$ \\
\hline 2 & NI & $\begin{array}{c}\text { SVT } \\
\text { (CL 200) }\end{array}$ & $\begin{array}{c}\text { SVT }^{*} \\
\text { (CL } 295 / 243 / 250)\end{array}$ & $\begin{array}{c}\text { SVT* }^{*} \\
\text { (CL. 300/286/292) }\end{array}$ \\
\hline 3 & $\mathrm{NI}$ & NI & NI & $\begin{array}{c}\text { SVT } \\
\text { (CL 238) }\end{array}$ \\
\hline 4 & NI & $\begin{array}{c}\text { SVT } \\
\text { (CL 178) }\end{array}$ & $\begin{array}{c}\text { SVT } \\
\text { (CL 200) }\end{array}$ & $-\dagger$ \\
\hline 5 & NI & NI & NI & NI \\
\hline 6 & NI & NI & NI & $\begin{array}{c}\text { SVT } \\
\text { (CL 214) }\end{array}$ \\
\hline 7 & NI & $\begin{array}{c}\text { SVT } \\
\text { (CL 167) }\end{array}$ & $\begin{array}{c}\text { SVT } \\
\text { (CL 233) }\end{array}$ & $\begin{array}{c}\text { SVT } \\
\text { (CL 214) }\end{array}$ \\
\hline 8 & NI & NI & $\mathrm{NI}$ & $\begin{array}{c}\text { SVT } \\
\{\mathrm{CL} \mathrm{167)}\end{array}$ \\
\hline
\end{tabular}

$\mathrm{NI}=$ Noninducible; NSVT $=$ nonsustained ventricular tachycardia; $\mathrm{SVT}=$ sustained ventricular tachycardia; $\mathrm{CL}=$ ventricular tachycardia cycle length expressed in milliseconds.

*Ventricular tachycardias of various cycle lengths and morphologies were initiated during repeated testing.

tThe final pirmenol infusion resulted in spontaneous lethal ventricular tachyarrhythmia, which was preceded by a severe reduction in blood pressure.

noninfarcted and in infarcted ventricular myocardium by means of modified previously described methods. ${ }^{13}$ Strength-interval curves were constructed at a basic drive cycle length of $400 \mathrm{msec}$ (heart rate $150 \mathrm{bpm}, 2.5 \mathrm{~Hz}$ ), with the current for the drive beats held constant throughout the determination at twice the minimum diastolic threshold for excitability. During generation of the strengthinterval relationship, an extrastimulus $\left(\mathrm{S}_{2}\right)$ was introduced into late diastole at a minimum milliamperage (ventricular excitation threshold) for eliciting a ventricular response $\left(\mathrm{V}_{2}\right)$. The coupling interval of $\mathrm{S}_{2}$ was then decreased incrementally until $\mathrm{S}_{2}$ failed to elicit a $\mathrm{V}_{2}$. When $\mathrm{S}_{2}$ failed to elicit a $V_{2}$, the milliamperage of $S_{2}$ was increased until a $V_{2}$ was elicited, and the coupling interval was further decreased until $S_{2}$ again failed to elicit a $V_{2}$. The sequence was repeated until a ventricular effective refractory period (ERP) was reached at a maximum current of $4 \mathrm{~mA}$. The ventricular ERP, therefore, was defined as the longest $S_{1}-S_{2}$ interval that failed to elicit a $\mathrm{V}_{2}$ at $4 \mathrm{~mA}$. The relative refractory period (RRP) was defined as the longest $S_{1}-S_{2}$ coupling interval along the strength-interval curve at which the current required to evoke a $V_{2}$ response increased above the diastolic excitation threshold by greater than $0.025 \mathrm{~mA}$ for a $1 \mathrm{msec}$ change in coupling interval.

Programmed ventricular stimulation protocol. Electrocardiographic intervals and electrophysiologic parameters were determined immediately before programmed stimulation testing. Electrocardiographic intervals were determined during sinus rhythm. A rate-corrected QT interval $\left.\left(\mathrm{QT}_{\mathrm{c}}=\mathrm{QT} \text { in msec/[R-R in sec }\right]^{1 / 4}\right)$ was determined during atrial pacing at $2.5 \mathrm{~Hz}$ (model S-44 stimulator, Grass Instrument Co., Quincy, Mass.). Right ventricular outflow tract excitation threshold voltage and refractory period also were determined during $2.5 \mathrm{~Hz}$ atrial pacing.
During the programmed ventricular stimulation protocol, premature ventricular stimuli $(4 \mathrm{msec}$ duration, $2 \times$ threshold) were introduced into the interventricular septum (right ventricular outflow tract, RVOT) using a model S-88 stimulator and an SIU-5 stimulus isolation unit (Grass Instrument Co.). Single $\left(\mathrm{S}_{2}\right)$, double $\left(\mathrm{S}_{2} \mathrm{~S}_{3}\right)$ and then triple $\left(\mathrm{S}_{2} \mathrm{~S}_{3} \mathrm{~S}_{4}\right)$ premature ventricular stimuli were introduced. Single ventricular extrastimuli were introduced during atrial pacing at $S_{1}-S_{2}$ coupling intervals decreasing from $350 \mathrm{msec}$ until ventricular refractoriness occurred. The RVOT excitation threshold voltage was defined as the minimum voltage required to produce a conducted ventricular beat $\left(V_{2}\right)$ at a stimulus duration of 4 msec delivered 350 msec after the $R$ wave of the lead II ECG. The RVOT refractory period was the longest $R$ to $S_{2}$ interval at which a $2 \times$ threshold stimulus failed to produce a $V_{2}$ response. Thereafter, double and triple ventricular extrastimuli were introduced during sinus rhythm at $S_{2}-S_{3}$ and $S_{2}-S_{3}-S_{4}$ coupling intervals of 182,167 , $154,143,133$, and 125 msec. Previous work has shown that this method fails to produce ventricular dysrhythmias in sham-operated animals without previous myocardial ischemic injury. ${ }^{14}$

Plasma pirmenol assay. Arterial blood samples were obtained immediately before electrophysiologic testing and after the cumulative administration of $2.5,5$ and 10 $\mathrm{mg} / \mathrm{kg}$ pirmenol. Pirmenol concentrations in plasma were determined by the Department of Drug Metabolism and Pharmacokinetics at Warner-Lambert/Parke-Davis (Morris Plains, N.J.) using a high-performance liquid chromatographic procedure..$^{15}$

Postmortem quantification of myocardial infarct size. At the conclusion of each experiment, the hearts were excised and cut into $1 \mathrm{~cm}$ thick sections from apex to base, parallel to the atrioventricular groove. The heart sections 
Table II. ECG and electrophysiologic responses $(\mathrm{N}=8)$

\begin{tabular}{|c|c|c|c|c|}
\hline \multirow[b]{2}{*}{ Parameter } & \multirow[b]{2}{*}{ Predrug } & \multicolumn{3}{|c|}{ Pirmenol (mg/kglli) } \\
\hline & & 2.5 & 5 & 11 \\
\hline Heart rate & $119 \pm 4$ & $129 \pm 5$ & $1: 7 \pm 7$ & $128 \pm 11$ \\
\hline Mean arterial pressure ( $\mathrm{mm} \mathrm{Hg})$ & $92 \pm 5$ & $92 \pm 5$ & $81 \pm 4$ & $35 \pm 5+$ \\
\hline PR interval (msec) & $121 \pm 4$ & $123 \pm 3$ & $1.3 .3 \pm 6$ & $141 \pm 6^{\circ}$ \\
\hline QRS interval (msec) & $61 \pm 1$ & $62 \pm 2$ & $64 \pm 2$ & $67 \pm 2$ \\
\hline $\mathrm{QT}_{\mathrm{c}}$ interval (msec) $(\mathrm{sec})^{-1}$ & $305 \pm 11$ & $308 \pm 16$ & $326 \pm 7$ & $1329+10$ \\
\hline Paced QT interval (msec) & $214 \pm 7$ & $216 \pm 7$ & $214 \pm 5$ & $293 \pm 7$ \\
\hline Ventricular excitation threshold $(\mathrm{V}) \dagger$ & $1.2 \pm 0.2$ & $1.4 \pm 0.3$ & $1.4 \pm 0.3$ & $3.5 \pm 10.3$ \\
\hline Ventricular refractory period (msec)t & $152 \pm 6$ & $161+6$ & $160 \pm 8$ & 1508 \\
\hline
\end{tabular}

${ }^{*} \mathrm{p}<0.05$ compared with predrug value.

†Determined at the right ventricular outflow tract site.

were incubated in $0.5 \%$ wt/vol triphenyltetrazolium chloride (Sigma Chemical Co., St. Louis, Mo.) and phosphate buffer (0.1 M, pH 7.4) for 15 minutes. Triphenyltetrazolium produces a distinctive red when reduced by intracellular dehydrogenases in viable, noninfarcted tissue. After incubation in triphenyltetrazolium, the unstained area of infarction was measured as a percentage of total left ventricle via gravimetric analysis.

Drug administration. Pirmenol (Warner-Lambert/ Parke-Davis) was provided as a monohydrochloride salt. Indicated dosages represent amounts of the base compound. Normal saline solution $(0.9 \%$ wt/vol $\mathrm{NaCl})$ was used as a vehicle throughout, with the cumulative 10 $\mathrm{mg} / \mathrm{kg}$ dose of pirmenol delivered in a total volume of 50 $\mathrm{ml}$. The drug dosages used in the present study were based on the results of previously reported experimental antiarrhythmic evaluations of this agent. . $^{6-8}$

Statistical analysis. All data are expressed as mean \pm SEM. Pre- and posttreatment values were compared by an analysis of variance for multigroup repeated measures, followed by a Dunnett's test for multiple comparisons to one control (pretreatment) group. The criterion for statistical significance was $p<0.05$.

\section{RESULTS}

Response to programmed ventricular stimulation. The responses of postinfarction dogs to programmed ventricular stimulation before and after the cumulative administration of $2.5,5$ and $10 \mathrm{mg} / \mathrm{kg}$ pirmenol are summarized in Table I. Before pirmenol administration, all eight dogs were determined to be nonresponsive to programmed ventricular stimulation in the anesthetized state. In seven of the eight dogs, administration of pirmenol in the dosage range of 2.5 to $10 \mathrm{mg} / \mathrm{kg}$ made it possible to initiate ventricular tachyarrhythmia (VT) by programmed ventricular stimulation using the same pacing protocol used during the predrug testing period. Six of the animals responded to postdrug testing with sustained VTs, with three of six dogs displaying sustained VT at the initial pirmenol dosage of 2.5 $\mathrm{mg} / \mathrm{kg}$ and greater, and the remaining three responding with sustained VT only after the administration of $10 \mathrm{mg} / \mathrm{kg}$ pirmenol. In one of the six pirmenol-treated dogs displaying sustained VT, the last drug infusion resulted in spontaneous develop. ment of lethal ventricular tachyarrhythmia, which was preceded by a severe reduction in blood pressure. Of the two remaining noninducible dogs entered into this study, one responded with a reproducible nonsustained ventricular tachycardia (15 to 20 monomorphic beats in duration) after the administration of $5 \mathrm{mg} / \mathrm{kg}$ pirmenol, while the final animal remained noninducible throughout the dosing protocol (Table I).

Table II summarizes the pre- and posttreatment values for ECG intervals, sinus heart rate, mean arterial pressure, and for ventricular excitation threshold voltage and refractory period determined at the RVOT site. Intravenous pirmenol administration to the postinfarction dogs resulted in a progressive decrease in mean arterial pressure $(p<0.05$ at $10 \mathrm{mg} / \mathrm{kg}$ ) and increases in both the PR and QRS intervals ( $p<0.05$ at $10 \mathrm{mg} / \mathrm{kg}$ ). The paced QT and rate-corrected QTc intervals were prolonged slightly, but not significantly, by pirmenol administration.

Electrophysiologic responses in normal noninfarcted and in infarcted ventricular myocardium. Before pirmenol administration, the ventricular excitation threshold value determined in infarcted myocardium was significantly greater than that of the noninfarcted region, whereas predrug values for the relative and effective refractory periods did not differ significantly between the two zones. This lack of disparity in refractoriness between the infarcted and noninfarcted areas of myocardium in the predrug setting may reflect the relatively small size of infarcted tissue recruited for the construction of the strength-interval curves. Administration of intravenous pirmenol failed to alter values for ventricular 


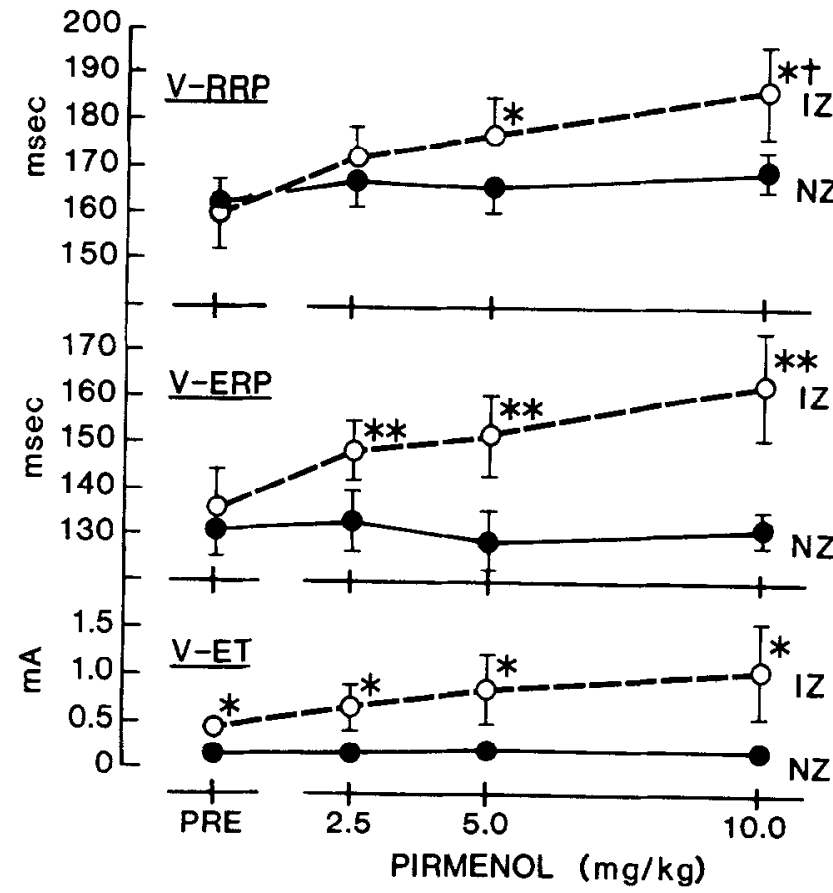

Fig. 2. Effect of pirmenol on ventricular excitation threshold (V-ET), effective refractory period (V-ERP), and relative refractory period $(V-R R P)$. These values were determined before ( $P R E$ ) and after the cumulative administration of $2.5,5$, and $10 \mathrm{mg} / \mathrm{kg}$ pirmenol in hoth normal noninfarcted ( $N Z$, solid circles, solid lines) and in infarcted (IZ, open circles, broken lines) zones of ventricular myocardium. Each point represents mean \pm SEM with $\mathrm{N}=8$. $\dagger p<0.05$ compared with appropriate $P R E$ values; ${ }^{*} p<0.05{ }^{* *} p<0.01 I Z$ value compared with corresponding $N Z$ value.

excitation threshold or relative and effective refractory periods determined in normal noninfarcted myocardium (Fig. 2). During pirmenol infusion, excitation thresholds determined in infarcted tissue increased in magnitude and variability, while infarct zone effective and relative refractory periods increased in a dose-dependent fashion, with the latter parameter differing significantly $(p<0.05)$ from its predrug value after administration of 10 $\mathrm{mg} / \mathrm{kg}$ pirmenol (Fig. 2). Of primary importance was the fact that the administration of pirmenol resulted in the development of significant differences between paired noninfarcted vs. infarcted zone values for both the relative refractory period $(p<0.05$ after 5 and $10 \mathrm{mg} / \mathrm{kg}$ pirmenol) and the effective refractory period $(p<0.01$ after $2.5,5$, and $10 \mathrm{mg} / \mathrm{kg}$ pirmenol), where no such difference or disparity had existed before drug administration (Fig. 2). Infarct zone values for excitation threshold continued to exceed $(p<0.05)$ paired noninfarct zone values during drug administration (Fig. 2).
Plasma concentrations of pirmenol. The cumulative administration of $2.5,5$, and $10 \mathrm{mg} / \mathrm{kg}$ pirmenol to postinfarction dogs resulted in mean plasma pirmenol concentrations of $1.18 \pm 0.17,2.21 \pm 0.34$, and $3.36 \pm 0.55 \mu \mathrm{g} / \mathrm{ml}$, respectively. Plasma pirmenol concentrations achieved in this study ranged from 0.55 to $6.81 \mu \mathrm{g} / \mathrm{ml}$. In animal Nos. 2, 4, and 7 (Table I), sustained VTs were initiated after administration of $2.5 \mathrm{mg} / \mathrm{kg}$ pirmenol, yielding plasma pirmenol concentrations of $1.11 \pm 0.16 \mu \mathrm{g} / \mathrm{ml}$. Sustained VTs were initiated in animal Nos. 3, 6, and 8 (Table I) after the administration of $10 \mathrm{mg} / \mathrm{kg}$ pirmenol, yielding plasma pirmenol concentrations of $3.15 \pm$ $0.58 \mu \mathrm{g} / \mathrm{ml}$. A plasma pirmenol concentration of 6.81 $\mu \mathrm{g} / \mathrm{ml}$ was associated with the development of hemodynamic compromise and spontaneous lethal arrhythmia in animal No. 4 (Table I).

Postmortem quantification of infarct size. The sizes of the underlying anterior myocardial infarcts in the eight pirmenol-treated dogs were determined to be $10.2 \% \pm 2.1 \%$ of the total left ventricle. In recent antiarrhythmic and electrophysiologic evaluations in this laboratory, postinfarction dogs that were responsive to initiation of VT by programmed ventricular stimulation using a pacing protocol identical to that used in this study possessed anterior infarctions ranging from $18.9 \pm 2.0 \%$ to $25.6 \% \pm 2.6 \%$ of the total left ventricle. ${ }^{16-20}$ Postinfarction dogs that were nonresponsive to the present programmed stimulation protocol in two previous evaluations possessed anterior infarctions comprising $5.3 \% \pm$ $1.1 \%$ and $7.1 \% \pm 1.4 \%$ of the total left ventricle. ${ }^{18,21}$ A previous evaluation of the arrhythmogenic actions of lidocaine used dogs with anterior infarctions comprising $8.6 \% \pm 4.0 \%$ of the total left ventricle. ${ }^{5}$

\section{DISCUSSION}

Electrophysiologic testing for the evaluation of proarrhythmic drug responses. Clinical investigations have advanced the use of programmed ventricular stimulation for the systematic evaluation of proarrhythmic responses to antiarrhythmic therapy in patients referred for study because of ventricular arrhythmias. ${ }^{2-4}$ Initial studies using programmed stimulation techniques have reported overall incidences of the aggravation or provocation of ventricular arrhythmias in $13 \%$ to $16 \%$ of conventional and investigational antiarrhythmic drug tests ${ }^{3,4}$ occurring in $13 \%$ to $30 \%$ of patients studied. ${ }^{2-4} \mathrm{~A}$ similar incidence of proarrhythmic response to antiarrhythmic therapy, $11 \%$ of drug tests in $34 \%$ of patients, has been demonstrated using ambulatory ECG monitoring and exercise testing. ${ }^{1}$ Programmed ventricu- 
lar stimulation testing, therefore, may predict proarrhythmic drug responses with an overall incidence approximating that reported by ambulatory monitoring techniques and offers the advantages of less variability in response and earlier detection of potential proarrhythmic actions. Electrophysiologic testing additionally permits a more thorough evaluation of the mechanism sof proarrhythmic action of antiarrhythmic agents, which should result ultimately in the development of antiarrhythmic therapies with minimal proarrhythmic potential.

Effects of pirmenol on the response to programmed ventricular stimulation. In the present study, the electrophysiologic actions of intravenous pirmenol were evaluated in dogs with recent myocardial infarction but nonresponsive to programmed ventricular stimulation testing in the pretreatment setting. After the cumulative administration of 2.5 to $10 \mathrm{mg} / \mathrm{kg}$ pirmenol, programmed pacing techniques identical to those used in the pretreatment setting initiated sustained VTs in six of eight postinfarction dogs tested, with one additional animal responding to programmed stimulation with nonsustained ventricular tachycardia after pirmenol. Pirmenol facilitated the initiation of ventricular tachycardia in postinfarction dogs with underlying anterior myocardial infarcts markedly smaller in size than those found in inducible postinfarcted dogs in previous investigations in this laboratory ${ }^{16-20}$ Additionally, the rates of the VTs initiated in the pirmenoltreated dogs tended to be slower than those initiated in inducible postinfarction dogs during pretreatment testing in previous studies. ${ }^{16-20}$ The pirmenol plasma concentrations achieved in the present investigation were comparable to those determined effective in the suppression of spontaneous ventricular ectopy in dogs 24 to 48 hours after experimental myocardial infarction ${ }^{7}$ and in reducing the frequency of premature ventricular contractions in patients with chronic ventricular ectopy. ${ }^{9.12}$

Clinical arrhythmogenic aspects of pirmenol. Preliminary clinical trial data have shown the incidence of arrhythmogenic responses to pirmenol to be minimal.* In one multicenter oral dose-response study, where $92 \%$ of the patients had cardiac disease, the incidence of reported arrhythmogcnic responses during the double-blind period was less than $2 \%$ (three of 148 pirmenol treated patients). Two of these three patients were titrated with higher pirmenol doses in the open-label period with beneficial results and an absence of side effects. In a multicent-

* Clinical Ressearch Department. Parke-I)avis Div. of Warner Lambert, Morris Plains, N.I er noncomparative study in patients with a history of sustained VT or symptomatic nonsustained VT followed by electrophysiology assessment, the incidence of arrhythmogenic responses after intravenous pirmenol was $6 \%$ (five of 89 tested patients) whereas $19 \%$ of the patients were noninducible. A multicenter study is in progress in which intravenous pirmenol is being compared with intravenous lidocaine for the treatment of warning ventricular arrhythmias subsequent to acute myocardial infarction. While the study is double-blind, early findings ( $\mathbf{n}=30$ patients) suggest that pirmenol is at least as effective as lidocaine with fewer side effects in this setting. No arrhythmogenic responses have been reported to date in the conduct of this trial.

Electrophysiologic actions of pirmenol. In vitro studies in canine Purkinje fibers have shown pirmenol to decrease action potential amplitude and upstroke velocity $\left(\dot{\mathrm{V}}_{\max }\right)$, shorten the action potential duration $\left(A P D_{50}\right)$, increase the effective refractory period, and depress membrane responsiveness in a manner similar, but not identical, to currently available "local anesthetic" class I antiarrhythmic agents. ${ }^{22}$ Pirmenol's ability to depress the rate of cellular depolarization $\left(\dot{\mathrm{V}}_{\max }\right.$, a cellular correlate for conduction velocity at the tissue level) would be consistent with the prolongation in the QRS duration observed after the $10 \mathrm{mg} / \mathrm{kg}$ drug dosage by virtue of a depression in ventricular conduction velocity. A class I type depression in ventricular conduction also might account for the relatively slower rates of ventricular tachycardia initiated in the pirmenol-treated dogs in this study.

Previous investigators have speculated that a basic electrophysiologic mechanism underlying the abilities of antiarrhythmic agents to aggravate or provoke ventricular arrhythmias is a critical slowing in ventricular conduction (i.e., delayed activation times) with only minimal increases in refractoriness in potential reentrant pathways, thereby facilitating the development of reentrant VTs. " Patterson et al. ${ }^{5}$ demonstrated that selective increases in activation delays and refractoriness in ischemically injured ventricular myocardium occur concomitantly with the facilitation of ventricular tachycardia initiation by lidocaine in postinfarction dogs. In the present study, pirmenol similarly increased refractoriness selectively in ischemically injured myocardium and increased the disparity in refractoriness between normal noninjured and ischemically injured myocardium. A depression in ventricular conduction through a class I-type electrophysiologic action, in conjunction with a selective increase in refractoriness in ischemically injured ventricular 
tissue, may contribute to the ability of pirmenol and similar conventional and investigational class I antiarrhythmic agents to facilitate the development of VTs in the presence of recent ischemic injury.

Conclusions. The initiation of VT by programmed ventricular stimulation was facilitated by pirmenol, an investigational class I antiarrhythmic agent, in seven of eight previously noninducible postinfarction dogs tested. Pirmenol tended to increase refractoriness selectively in ischemically injured ventricular myocardium and significantly increased the difference or dispersion of refractoriness between normal noninjured and ischemically injured tissue. The results suggest a potential for the aggravation or provocation of ventricular arrhythmias by pirmenol, as well as similar conventional and investigational class I antiarrhythmic agents, in the presence of recent ischemic injury.

We gratefully acknowledge Drs. Harvey Kaplan, Dale B. Evans, and Tsun Chang of Warner-Lambert/Parke-Davis for their suggestions in the preparation of this manuscript and their assistance in the determination of plasma pirmenol concentrations. We also thank Ms. Kim Kanitz for her expert preparation of the manuscript

\section{REFERENCES}

1. Velebit V, Podrid P, Lown B, Cohen BH, Graboys TB. Aggravation and provocation of ventricular arrhythmias by antiarrhythmic drugs. Circulation 1982;65:886.

2. Rinkenberger RL, Prystowsky EN, Jackman WM, Naccarelli GV, Heger JJ, Zipes DP. Drug conversion of nonsustained ventricular tachycardia to sustained ventricular tachycardia during serial electrophysiologic studies: identification of drugs that exacerbate tachycardia and potential mechanisms. Am Heart J 1982;103:177.

3. Torres V, Flowers D, Somberg JC. The arrhythmogenicity of antiarrhythmic agents. Am Heart J 1985;109:1090.

4. Poser RF, Podrid PF, Lombardi F, Lown B. Aggravation of arrhythmia induced with antiarrhythmic drugs during electrophysiologic testing. Am Heart J 1985;110:9

5. Patterson E, Gibson JK, Lucchesi BR. Electrophysiologic actions of lidocaine in a canine model of chronic myocardial ischemic damage - arrhythmogenic actions of lidocaine. $\mathrm{J}$ Cardiovasc Pharmacol 1982;4:925.

6. Steffe TJ, Mertz TE, Hastings SG, Potoczak RE, Kaplan HR. CI-845 (pirmenol hydrochloride): a new orally effective longacting antiarrhythmic agent. $J$ Pharmacol Exp Ther 1980;214:50.

7. Mertz TE, Steffe TJ. Pirmenol hydrochloride (CI-845): anti- arrhythmic profile in coronary artery ligated conscious dogs. J Cardiovasc Pharmacol 1980;2:527.

8. Mertz TE, Kaplan HR. Pirmenol hydrochloride (CI-845) and reference antiarrhythmic agents: effects on early ventricular arrhythmias after acute coronary artery ligation in anesthe tized rats. J Pharmacol Exp Ther 1982;223:580.

9. Hammill SC, Shand DG, Routledge PA, Hindman MC, Baker JT, Pritchett ELC. Pirmenol, a new antiarrhythmic agent: initial study of efficacy, safety and pharmacokinetics. Circulation 1982;65:369.

10. Anderson JL, Lutz JR, Sanders SW, Nappi JM. Efficacy of intravenous pirmenol hyddrochloride for treatment of ventricular arrhythmias: a controlled comparison with lidocaine. J Cardiovasc Pharmacol 1983;5:213.

11. Lee TG, Goldbert AD, Chang T, et al. Pharmacokinetics and efficacy of pirmenol hydrochloride in the treatment of ventricular dysrhythmia. J Cardiovasc Pharmacol 1983;5:632.

12. Anderson JL, Lutz JR, Nappi JM. Pirmenol for control of ventricular arrhythmias: oral dose-ranging and short-term maintenance study. Am J Cardiol 1984;53:522.

13. Michelson EL, Spear JF, Moore EN. Electrophysiologic and anatomic correlates of sustained ventricular tachyarrhythmias in a model of chronic myocardial infarction. Am $J$ Cardiol 1980;45:583.

14. Patterson E, Holland K, Eller BT, Lucchesi BR. Ventricular fibrillation resulting from ischemia at a site remote from previous myocardial infarction. A conscious canine model of sudden coronary death. Am J Cardiol 1982;50:1414.

15. Johnson EL, Pachla LA. Improved liquid chromatographic assay for the analysis of pirmenol in plasma and urine. $J$ Pharm Sci 1984;73:754.

16. Lynch JJ, Wilber DJ, Montgomery DG, Hsieh TM, Patterson $\mathrm{E}$, Lucchesi BR. Antiarrhythmic and antifibrillatory actions of the levo- and dextrorotatory isomer of sotalol. J Cardiovasc Pharmacol 1984;6:1132.

17. Wilber DJ, Lynch JJ, Pitt B, Lucchesi BR. Protective effect of alpha 1 blockade in a conscious canine model of sudden death. Circulation 1984;70(suppl II):II-179.

18. Wilber DJ, Lynch JJ, Montgomery DG, Lucchesi BR. Postinfarction sudden death: significance of inducible ventricular tachycardia and infarct size in a conscious canine model. Am Heart J 1985;109:8.

19. Lynch JJ, Coskey LA, Montgomery DG, Lucchesi BR. Prevention of ventricular fibrillation by dextrorotatory sotalol in a conscious canine model sudden coronary death. Am Heart J $1985 ; 109: 949$

20. Lynch JJ, Montgomery DG, Ventura A, Lucchesi BR. Antiarrhythmic and electrophysiologic effects of bepridil in chronically infarcted conscious dogs. J Pharmacol Exp Ther 1985;234:72.

21. Lynch JJ, Montgomery DG, Lucchesi BR. Facilitation of lethal ventricular arrhythmias by therapeutic digoxin in conscious postinfarction dogs. Am Heart J 1986; 111:883.

22. Reder RF, Danilo P, Rosen MR. Effects of pirmenol $\mathrm{HCl}$ on electrophysiologic properties of cardiac Purkinje fibers. Eur J Pharmacol 1980;61:321. 